\title{
Um evento de (bi)letramento em língua indígena: reflexos de uma política linguística Terena ${ }^{1}$
}

\author{
Onilda Sanches Nincao ${ }^{2}$ \\ UFMS - Aquidauana \\ onilda.sanches@ufms.br
}

\section{Resumo}

Este texto apresenta dados de pesquisa realizada junto a professores indígenas a partir de oficinas de produção de textos em língua Terena que tiveram como objetivo produzir textos nessa língua a fim de servirem à produção de material didático na escola. A metodologia adotada seguiu os preceitos sugeridos por Vóvio e Souza (2005) para pesquisas na área de Linguística Aplicada que focalizam práticas sociais de letramento. As oficinas de produção de textos em língua Terena tiveram a participação de 16 professores indígenas. Os dados foram analisados a partir do pressuposto de que (a) em contextos bilíngues, as línguas não ocupam compartimentos isolados (Maher, 2007a), (b) há uma conjunção entre as práticas de letramento nas duas línguas em questão (Hornberger, 1989/2003) e (c) o letramento não tem o mesmo significado nos diferentes contextos culturais (Street, 2006). Os resultados demonstraram que o biletramento que emergiu nas oficinas de textos focalizadas evidencia um procedimento cultural Terena que encontra justificativa nas construções identitárias desse povo ao longo da história, emergindo a escrita em uma função simbólica de indianidade Terena, com força política e combativa.

Palavras-chave: texto, professor indígena, língua Terena.

\footnotetext{
Abstract

This paper presents data from research with indigenous teachers at text

${ }^{1}$ Pesquisa realizada como bolsista da FUNDECT - Fundação de Apoio ao Desenvolvimento do Ensino, Ciência e Tecnologia do Estado do Mato Grosso do Sul.

${ }^{2}$ Doutora em Linguística Aplicada (UNICAMP).
} 
production workshops in Terena language. Such workshops aimed to produce texts in this language in order to serve the production of teaching materials at schools. The adopted methodology followed the precepts suggested by Vóvio and Souza (2005) for research in the area of Applied Linguistics, which focus on the social practices of literacy. Sixteen indigenous teachers took part in the workshops. The data were analyzed from the assumption that (a) in bilingual contexts, languages do not occupy isolated compartments (Maher, 2007a), (b) there is a conjunction between literacy practices in the two languages in question (Hornberger, 1989 / 2003) and (c) literacy does not have the same meaning in different cultural contexts (Street, 2006). The results demonstrated that the biliteracy that emerged from the workshops of focused texts reflects a cultural Terena procedure that finds justification in this people's identity constructions throughout history. Thus, writing emerges into a symbolic function of Terena Indianness, with political and combative force.

Keywords: text, indigenous teacher, Terena language.

\section{Introdução}

O século XXI trouxe mudanças ocasionadas por inúmeros fatores, tais como: avanços tecnológicos de várias ordens e em vários níveis, novas configurações políticas que levaram a mudanças geográficas, sociais, entre outras, e o fenômeno da globalização que aproxima a humanidade. No bojo dessas mudanças, os povos indígenas brasileiros foram alcançados. A partir de lutas de movimentos organizados em busca de seus direitos nos contextos sociais e étnicos, o governo brasileiro foi obrigado a atender suas reivindicações (embora não todas), garantindo-lhes direitos na Constituição de 1988. O direito à educação passa a garantir cada vez mais o processo de escolarização dos povos indígenas brasileiros, buscando-se a construção de uma escola indígena diferenciada, específica, intercultural e bilíngue (DIRETRIZES, 1994). Nesse percurso, buscam reconstruir seus saberes étnicos, incluindo-se os saberes linguísticos.

Os povos indígenas começaram, assim, a dar a cara no cenário brasileiro, tornando-se visíveis para uma 
sociedade que considerava índios como figuras de livro didático. O Estado do Mato Grosso do Sul, por exemplo, congrega a segunda maior população indígena do Brasil com nove povos indígenas e, conforme dados do IBGE/2012 uma população de 73295 pessoas: Terena, Guarani-Nhandeva, Guarani-Kaiowá, Kinikinau, Kadwéu, Guató, Ofaye-Xavante, Kamba (vindos da Bolívia) e Atikum (vindos do Pernambuco).

Com o objetivo de contribuir ainda mais para a visibilização dos povos indígenas brasileiros, este texto apresenta ao leitor a forma como o povo Terena, habitante do pantanal sul-mato-grossense, estabelece estratégias deliberadas de sobrevivência, não só física, mas principalmente étnica. Entre suas diversas estratégias, trato, neste texto, de sua política linguística.

A consciência da obrigatoriedade do contato com a sociedade nacional apontada por Ladeira (2001) - e por mim testemunhada, em diversas ocasiões, em minha convivência com os Terena desde 1995 - faz que eu entenda tal consciência como parte constitutiva de sua identidade étnica, identidade essa frequentemente mal compreendida. Ouvi uma vez de um líder Terena uma afirmação utilizada para contestar sua fama de índios domesticados, de índios passivos: "Professora, nós não somos passivos, nós somos diplomáticos!”. E ser diplomático significa entender que o diálogo intercultural, por ser sempre tenso e difícil (MAHER, 2007b), demanda a utilização de estratégias para não sucumbir ao Outro. Para o povo Terena, não sucumbir ao Outro significa, entre outras coisas, dominar a língua do Outro (Ladeira, 2001). Aprender a Língua Portuguesa não é visto, portanto, pelos Terena como um ato de sujeição, mas como uma estratégia diplomática de sobrevivência. O não isolamento sempre foi, para os Terena, o caminho para a sobrevivência étnica. E, se já o era anteriormente, quando nada mais eram do que bugres (OLIVEIRA, 1968, 1976), muito mais é agora, quando conquistam o direito a serem cidadãos (OLIVEIRA, 2006). ${ }^{3}$

3 Esse autor aponta o fato de que, a partir dos anos 70, “os índios e suas lideranças passaram a demandar um respeito às suas formas de ser - sua 
O aprendizado do Português faria parte, então, de "uma política deliberada e consciente da comunidade e não decorrência aleatória de interferências externas" (LADEIRA, 2001, p. 130). Nesse sentido, este texto apresenta um evento de letramento ocorrido entre os Terena das aldeias Passarinho e Cachoeirinha, no município de Miranda, Mato Grosso do Sul. A seguir, posiciono-me no que se refere ao papel do letramento entre os povos indígenas.

\section{Os novos estudos do letramento e a escrita entre os povos indígenas}

No Brasil, as práticas de letramento em língua indígena (LI) são recentes. A partir da Constituição de 1988 e legislações posteriores, foi implementada uma nova política nacional de educação escolar indígena que conferiu um novo status às línguas indígenas, inserindo-as no espaço prestigioso da escola. Embora, essa tenha sido uma estratégia considerada importante, não foi suficiente, para a manutenção dessas línguas, como apontam inúmeros autores (conferir, por exemplo, MORI, 1997, 2001; VEIGA, 2001; MONSERRAT, 1994, 2001; D'ANGELIS, 2005 e MAHER 2006b).

É importante esclarecer que a passagem de uma língua de uma condição oral / ágrafa para a escrita não significa dizer que o grupo social que a usa se torne automaticamente letrado, no sentido de que sejam produtores de textos escritos

identidade e suas culturas tradicionais -, algo absolutamente até então inexistente. Foram reivindicações afirmadas no bojo do que ficou conhecido como o "Movimento Indígena" em escala nacional e a consequente criação de sua própria entidade étnica, denominada bem a propósito União das Nações Indígenas - UNI. A partir da ação quase pedagógica que essa entidade conseguiu realizar junto aos povos indígenas, sobretudo no que tange à autoestima e à recuperação do sentimento de dignidade requerida pela categoria de Índio vilipendiada durante toda a história do contato interétnico (...) - os índios atualmente passaram a assumir sua condição étnica com foros de uma nova cidadania que até então lhes era praticamente negada" (OLIVEIRA, 2006, p. 41,42). 
significativos e socialmente valorizados. Em Nincao (2003, p. 17, 18), já demostrei, com base em Meliá (1997), que é possível uma língua deixar de ser ágrafa, mas o povo que a usa continuar sendo iletrado, ou mesmo analfabeto, pois "uma sociedade de escrita não é necessariamente uma sociedade de leitura" (MELIÁ, op. cit., p. 101). E esse é o caso específico dos Terena, pois a língua não é mais ágrafa, por já contar com um sistema de escrita, mas possui pouquíssimos usuários desse sistema. No entanto, essa não é uma situação exclusiva do povo Terena: muitos outros grupos sociais, tanto no Brasil quanto em outros países, vivem suas vidas alheios às práticas escritas existentes.

Embora a inserção da escrita em português nas sociedades indígenas já seja, em sua maioria, uma realidade, nota-se que ela é um privilégio de um grupo reduzido dentro dessas sociedades, constituindo-se como objeto de elite aos moldes das elites cultas das sociedades ocidentais. Por outro lado, a valorização da escrita nas línguas indígenas encontra respaldo na iniciativa legal do Estado Brasileiro, que preconiza a inclusão no currículo de uma escola indígena que se quer específica, diferenciada, intercultural e bilíngue (DIRETRIZES, 1994; RCNEI, 1998; RESOLUÇÃO 03/99), incentivando o uso da língua indígena em sua modalidade escrita no processo de escolarização. Porém, na prática tem havido resistência dos próprios índios à escolarização em sua língua nativa, já que existe, entre outras razões, um temor de que se minimize o ensino do português como a língua que pode lhes dar acesso ao mundo do branco.

No que tange ao contexto específico discutido neste texto, é relevante esclarecer que entre as comunidades Terena de Aquidauana e Miranda ${ }^{4}$ a escrita vem causando reações diferentes. Enquanto em Aquidauana houve uma imposição governamental para o ensino da língua Terena na escola através

\footnotetext{
${ }^{4}$ Municípios localizados no pantanal sul-mato-grossense com populações do povo Terena.
} 
do Projeto Raízes do Saber ${ }^{5}$, contra o qual houve resistência da comunidade, em Miranda essa demanda parte da própria comunidade por meio dos professores indígenas que, como acadêmicos, se propõem a interferir em seu cenário sociocultural.

Tendo em vista esse contexto, cabe perguntar: que subsídios a teoria de letramento pode nos fornecer para entendermos a complexidade das questões envolvidas no letramento em língua indígena? O letramento, enquanto tema de reflexão teórica, tem como um de seus marcos iniciais a crítica feita pelo antropólogo Brian Street, em 1984, ao que ele denominou Modelo Autônomo de Letramento. Suas críticas recaíram sobre os resultados de pesquisas (GOODY, 1968, 1977,1987; ONG, 1986 e OLSON, 1997) que atribuíam à aquisição da escrita o aumento de capacidades cognitivas ditas superiores, tais como categorização, abstração e, consequentemente, o aumento de mobilidade social, prestígio etc. Nessa perspectiva, geralmente se pensa que, com a escrita, há um avanço, um progresso do homem: as sociedades ágrafas estariam em um estágio mais primitivo do que as sociedades letradas. Cavalcanti e Maher (2005) apontam que:

É relevante, também, relembrar que a sociedade
envolvente e dominante alimenta o mito do aprender a
ler e a escrever como a saída para todos os males, a
"redenção" do cidadão, sua "entrada no Paraíso" (grifos
das autoras), e ignora qualquer outro conhecimento que
não seja calcado na palavra escrita. (CAVALCANTI;
MAHER, 2005, p. 18)

Street enfatiza em seus estudos que os adeptos do Modelo Autônomo de Letramento não consideravam os contextos ideológicos onde se dava a aquisição da escrita, nem as condições particulares de sua produção e uso. A esse modelo,

\footnotetext{
${ }^{5}$ Projeto bilíngue implantado pela Prefeitura Municipal de Aquidauana em 1999 com o intuito de conferir obrigatoriedade à alfabetização em língua Terena.
} 
o autor contrapõe o Modelo Ideológico de Letramento, com o intuito de "situar as práticas de letramento no contexto do poder e ideologia, e não como uma habilidade neutra, técnica" (STREET, 2006, p. 465). Nessa mesma direção, Hornberger (1996, p. 8) argumenta que "o letramento nunca acontece em um vácuo".

A partir dos resultados das investigações conduzidas por Street e seus seguidores, compreendeu-se não ser produtivo a elaboração de grandes generalizações sobre os significados dos usos da escrita, já que os grupos sociais se apropriam da escrita de maneiras particulares, próprias. É nesse sentido que o autor argumenta, então, ser mais adequado falar em letramentos (STREET, 2006, p. 466), já que o termo é útil para expressar as diferentes formas como diferentes grupos sociais se apropriam e usam a escrita conforme seus interesses e objetivos específicos.

Como exemplo, apresento o episódio narrado por Levy-Strauss (1986, p. 290-301) quando discute o papel da escrita para a humanidade, classificando-o mais como sociológico do que intelectual, a partir de um fato acontecido entre os Nambikwara. O valor da escrita para esse povo indígena emergiu não como fruto de aprendizagem de uma técnica neutra, mas em sua força simbólica, na medida em que o chefe Nambikwara, mesmo sem o conhecimento necessário para utilizar a escrita, percebeu que poderia usá-la como fonte de prestígio e autoridade.

Com base em relatos de Reid (1988), Street (2006) apresenta as configurações do letramento, no sudeste asiático, no período que antecedeu o impacto ocidental:

Não se tratava de uma questão de elite nem de interesses comerciais, mas de uma variedade de costumes e práticas locais. A escrita nas Filipinas no século XVI, por exemplo, não servia a nenhum propósito religioso, jurídico ou histórico, mas era usada apenas para redigir notas e cartas. Em outros lugares, as mulheres usavam a escrita ativamente para trocar bilhetes e registrar dívidas, enquanto no sul de Sumatra, ainda em 1930, altas 
proporções da população empregavam o letramento para concursos de galanteio poético. (STREET, 2006, p. 473474)

Para a maioria dos povos indígenas, o letramento em língua indígena (LI) nos moldes do que Street (2006) chama de letramento dominante, isto é, um letramento imposto como uma necessidade para a condução da vida no cotidiano e que requer o domínio de uma técnica adquirida via alfabetização escolar, ainda não faz parte, de fato, de suas pautas culturais. $\mathrm{O}$ autor discute as implicações dessa postura, conforme se pode ver no trecho a seguir:

Era comum nas ciências sociais, até recentemente, encarar a sociedade como, antes de mais nada, um processo de dominação de cima para baixo, com a ideologia servindo aos propósitos de um grupo dominante e o resto como vítimas passivas ou relutantes. Recentemente, essa perspectiva foi substituída por outra que dá maior reconhecimento ao agenciamento (agency), ao modo como as pessoas em diferentes posições rejeitam e negociam as posições que aparentemente lhe são atribuídas. As implicações disso para os estudos do letramento são consideráveis: a aquisição de um conjunto particular de práticas de letramento, enquanto claramente associada a identidades culturais particulares, pode de fato ser um foco para transformação e desafio. (STREET, 2006, p.471)

É importante ressaltar as implicações da inserção da escrita nas comunidades indígenas, considerando-se que essa aporta em um contexto de bilinguismo diglóssico que, via de regra, já privilegiou a escrita do português. Dessa forma, o que se vê nas sociedades indígenas hoje, de maneira geral, é o uso oral de sua língua nativa e o uso escrito do português, uma vez que essa escrita só tem função/sentido na relação com a sociedade nacional.

Importa mais uma vez salientar, no entanto, que, em alguns casos, como entre os Terena, por muito tempo apenas 
uma elite era letrada em português, isto é, mantinha o domínio da forma e dos usos da escrita nessa língua, já que o processo de escolarização formal foi extremamente seletivo: para ter sucesso na escola do branco era necessário ter alguma condição de ordem pessoal (família, amigos) ou social para nela se manter. Hoje, essa situação começa a mudar, a partir da nova política nacional de educação escolar indígena.

Ao se inserir a língua indígena no processo escolar, é preciso também estar atento para a forma como a escrita em língua indígena adentrou o universo sociocultural de cada povo e como fortaleceu ou ameaçou as estruturas locais de poder. Grupos sociais que acessaram posições de poder a partir de suas competências comunicativas em português resistem à implementação da escrita em língua indígena, cuja valorização social, no médio prazo, pode alijá-los dessas posições de poder. Se a competência em língua portuguesa determinou o surgimento de grupos de elite, como no caso dos Terena, o que uma nova competência em língua indígena poderá ocasionar em termos políticos?

Segundo Hornberger (1996, p. 216- 236), a competência de uso de uma língua indígena em sua modalidade escrita pode empoderar o seu usuário. Analisando a história de três indivíduos falantes de Quéchua, no Peru, a autora demonstra como esses foram empoderados em suas comunidades devido a sua capacidade de leitura nessa língua. Lopez (1996, p. 327) também mostra como o letramento em LI é utilizado pelos Guarani na Bolívia como ferramenta para conscientização e mobilização social. Mas não são apenas políticos os benefícios trazidos pelo letramento em LI: Hornberger e King (1996, p. 313) fornecem evidências de como o letramento em língua Quéchua contribui para a sua revitalização. Street (2006) afirma que

Os responsáveis por ministrar o letramento tenderam a tratar os povos indígenas como tratariam alunos de escola, debatendo se estavam "prontos" (grifos do autor) para o letramento, se deveriam ter acesso a ele e que problemas estavam associados com seu "impacto" 
(grifos do autor). De um ponto de vista pedagógico, o processo é visto como a aquisição de específicas habilidades técnicas e o aprendizado das convenções e suposições sobre letramento sustentadas pelos professores.

Street (2006, p. 475) mostra que é preciso "assumir uma visão menos paternalista e menos pedagógica do processo", citando Kulik e Stroud (1990 apud STREET, 2006, p.476) quando afirmam que "em vez de sublinhar como o letramento afeta as pessoas, queremos mudar de lado e examinar como as pessoas afetam o letramento". Dessa forma, é importante considerar que essa escrita poderá não ser funcionalmente utilizada nas sociedades indígenas como foi historicamente nas sociedades ocidentais.

Tomando como base as discussões realizadas até aqui sobre letramentos situados, a relação letramento, cultura e poder e impactos do letramento, foi possível compreender a forma particular como os professores Terena focalizaram, de forma cultural e sociolinguisticamente significativa, as práticas de letramento nas Oficinas de Produção de Textos em LI.

\section{Línguas em interação}

Se os Novos Estudos do Letramento foram essenciais para compreender que existem apropriações específicas do letramento nos diferentes grupos sociais, o conceito de biletramento foi essencial para compreender a forma particular como se deu essa apropriação específica por professores Terena durante as oficinas de produção de texto em sua língua nativa (LI).

O termo biletramento foi utilizado por Hornberger (1989, 2001) para definir o contexto de letramento em duas línguas: "o biletramento pode ser definido como toda instância na qual a comunicação se desenvolve em duas (ou mais) línguas em torno de um texto escrito" (HORNBERGER, 2001, p. 26).

Para melhor compreender a forma como se dá essa

92 Horizontes de Linguística Aplicada, ano 11, n. 2, jul./dez. 2012 
situação, apresento, a seguir, um evento de letramento bilíngue que coordenei junto a professores Terena durante a realização de oficinas de produção de textos em LI, com 16 professores Terena pertencentes a duas aldeias dos Postos Indígenas Cachoeirinha e Pilad Rebuá (Aldeia Passarinho), do município de Miranda, localizado no pantanal sul-mato-grossense. Dentre os participantes, 13 professores eram egressos do Curso Normal Superior Indígena (CNSI) e três eram professores leigos. Dos 13 egressos do CNSI, oito são falantes fluentes da língua Terena (Aldeia Cachoeirinha): os demais são monolíngues em língua portuguesa.

Tendo escolhido o tema do primeiro texto a ser produzido, a história do Tuiuiú e o sapo, os professores Terena decidiram primeiro escrevê-lo em português (O Tuiuiú e o Sapo) para, depois, traduzi-lo para a língua indígena (Kóho Yoko Hovôvo).

Tal decisão foi surpreendente pelo fato de que as oficinas foram planejadas para oportunizar espaço para a língua Terena e não para a língua portuguesa, língua majoritária. Como pesquisadora, via as línguas separadas, em compartimentos estanques, mas o mesmo não acontecia com os professores Terena, para os quais as línguas estão relacionadas. Ao buscar uma explicação para o fenômeno, encontrei-a na teoria do biletramento elaborada pela pesquisadora Nancy Hornberger (1989, 2001), como já apresentado. Foi possível, assim, compreender que a decisão de escrever o texto nas duas línguas evidenciava a emergência do biletramento entre os Terena.

Instados a escrever em sua língua materna/nativa, o biletramento emergiu, nas oficinas de textos focalizadas, de forma a evidenciar um procedimento cultural Terena que encontra justificativa em suas construções identitárias ao longo da história - aprender a língua do outro sempre foi uma de suas estratégias políticas (LADEIRA, 2001). Dessa forma, razões sócio-políticas e identitárias determinam o letramento em LI relacionado ao letramento em LP, um biletramento. A relação entre a LP e a LI é, portanto, a primeira condição de produção de texto em Língua Terena. Conforme depoimento do Professor Genésio Farias: “(...) porque ficar só na língua indígena, ela 
VAI ISOLAR. A maior parte das pessoas, o próprio Terena, PRECISA desta escrita em Português" (Oficina 05/11/2005).

Nesse sentido, a política linguística desse povo oriunda do caráter historicamente expansionista dos Aruaque que os levava a deixar seu dialeto, cf. Ladeira (2001), configurou-se modernamente como uma política bilíngue de uso complementar das duas línguas. Como implicação dessa política para o letramento, o uso da LI oral cede lugar para a emergência de práticas de biletramento, em que o uso escrito da língua Terena ao lado da LP tem um valor simbólico de indianidade Terena no embate político com a sociedade nacional e para a própria coesão social interna, importante para as novas lutas. Isso foi constatado em um evento de letramento social em que o texto em língua Terena Kóho Yoko Hovôvo foi lido, pela primeira vez fora da escola, em uma ação de retomada de terra, no Acampamento Mãe Terra, na Aldeia Cachoeirinha.

Nessa ocasião, o texto foi lido por um professor indígena em língua Terena objetivando incentivar as famílias ali presentes a permanecerem no local diante de uma ameaça de despejo. A escrita em língua Terena assumiu ali um valor simbólico e político, ou seja, uma aliada na luta contra seu opressor, como afirmou também o Professor Genésio Farias em um de seus depoimentos: "Já é um texto de fazer o povo Terena pensar" (Prof. Genésio Farias) ${ }^{6}$.

O texto foi aí utilizado porque seu conteúdo temático aborda a relação de dominação a que estão sujeitos os Terena e suas estratégias de escape: um tuiuiú tenta engolir uma sapinho, mas esse abre as pernas quando percebe que o pescoço do tuiuiú é estreito e escapa de ser engolido. Os professores usaram a história para dizer que assim como o sapinho teve estratégia para não ser engolido pelo tuiuiú, os Terena também têm estratégias para não serem engolidos pela sociedade brasileira. E uma dessas estratégias é o domínio da língua portuguesa!

\footnotetext{
${ }^{6}$ Professor indígena, com formação superior, participante da pesquisa, falante da língua Terena, morador da aldeia Cachoeirinha, município de Miranda/MS.
}

94 Horizontes de Linguística Aplicada, ano 11, n. 2, jul./dez. 2012 
Diferentemente do que representações correntes sobre o impacto da escrita entre os povos indígenas prescreve(ra)m, a escrita não foi tomada nesse caso como uma imposição da sociedade ocidental, mas como uma arma contra a sociedade ocidental. Uma arma para conscientizar o próprio povo de suas perspectivas e potencialidades, como ocorrido na utilização do texto Kóho Yoko Hovôvo em seu sentido ideológico no Acampamento Mãe Terra. Esse sentido ideológico relaciona-se ao conteúdo da história do tuiuiú e o sapo. Referindo-se a um tema aparentemente banal, esse texto, no entanto, tem uma forte carga ideológica, já que, metaforicamente, o tuiuiú representa, na interpretação dos professores em questão, a sociedade nacional e o sapo, a sociedade Terena. Eis os textos, na ordem em foram produzidos:

Quadro 1: Texto produzido

na realização da atividade "Tuiuiü"

\section{O TUIUIÚ E O SAPO}

Certa vez, um índio passeava no Pantanal e avistou um raro espetáculo entre um sapo e um tuiuiú.

O tuiuiú, que estava observando o sapo, esperava a hora de aplicar seu bote certeiro e fulminante para acabar com aquele animal que, distraído, observava a natureza.

A certa altura, o tuiuiú aplicou o seu bote. O sapo foi pego de surpresa e uma luta começou a ser travada. Depois de muito esforço, o tuiuiú, com um movimento brusco, conseguiu jogar o sapo para cima e apará-lo no bico. Mas com um imprevisto o tuiuiú não contava: o sapo, com a sua esperteza, usou o seu último recurso: abrindo os braços e apertando o pescoço da garça, o sapo sufocou o tuiuiú, forçando-o a desistir do seu objetivo. 
Quadro 2: Texto produzido

na realização da atividade "Kóho Yoko Hovôvo"

\section{ко́но уоко HOVÔVO}

Ápe póhuti kopénoti, pihóne ya híyeuke pantaná yanê'e ápene noíxone póhuti hovôvo yoko póhuti kóho. Kuxó koyene ne kóho motovâti ákoyea kaítapa ra námui hovôvo.

Yane inámukone ne hovôvo ákotike yuixápa, itea koturikexovo ne hovôvo, Kahá 'ayea huîrikea ne kóho.

Yane pihóne káxe...

Ina eherúkoa kóho ne hovôvo ya kirikuke itea ako íta kóho huîrikea vo'oku, xemékepeovo kóturikeovo, xané kixoane namunokexea kóho koane kotítinuyea, yane ako íta xunako kóho ne hovôvo, yane itópovone ne hovôvo.

A escrita aqui institucionalmente alavancada (porque partiu da pesquisadora no contexto da universidade) não foi usada para grafar mitos, mas para gerar "mitos" contemporâneos, para produzir novas identidades também pelo discurso escrito, conforme a fala de um dos professores sobre o conteúdo ideológico do texto: " $E$, mas os Terena estão falando que não acreditam na derrota, não acreditam serem vencidos, continuam crendo na sua capacidade de sobreviver, de lutar" (Prof. Genésio Farias). E é nesse sentido que é preciso atentar para o fato de que a escrita em LI começa a ter um valor simbólico como forma de agregar valor à etnicidade Terena.

Como nos ensinou Street (1993, p. 1), é preciso compreender "as formas criativas e originais nas quais as pessoas transformam o letramento para seus próprios objetivos e interesses culturais". O biletramento que emergiu como uma política local, cultural e identitariamente determinada não é um fato irrelevante no quadro das discussões ocorridas no Brasil sobre ensino de língua indígena e formação de professores indígenas nos últimos anos. Enquanto lidávamos com a alfabetização indígena na perspectiva do letramento dominante (STREET, 2006), ou com os efeitos cognitivos da inserção da 
escrita por meio dessa alfabetização (modelo autônomo), não estávamos aptos a compreender a visão dos agenciadores locais. Foi preciso uma mudança teórica que acrescentasse ao termo letramento um S (Street,1984, 2006) e um BI (Hornberger, 1989,2003) compondo então a palavra BILETRAMENTOS, para se poder compreender as implicações da escrita em diferentes contextos socioculturais, como ocorreu nos dados focalizados, entre os Terena.

Esse evento de letramento em LI foi muito surpreendente para mim porque imaginava o texto preso ao contexto escolar onde foi produzido! Mas ele aparece ali, no Acampamento Mãe Terra, vivo, em uma situação real e significativa, embora aquelas pessoas não fossem alfabetizadas em língua Terena. Essa situação me fez lembrar Street (2006, p. 472) quando afirma que o "letramento dominante é apresentado como o único letramento", argumentando que para isso são usados "discursos públicos de neutralidade e tecnologia". Mas como sujeitos pós-modernos, contextualizados na sociedade globalizada, a escrita cumpre para os Terena, nesse momento, um papel simbólico e político e não mnemônico, pedagógico, tecnológico. Seu uso se dá muito mais para fazer frente à dominação a que estão sujeitos do que por uma necessidade de adquirir uma técnica para fazer um uso convencional de decifração de uma escrita alfabética.

Nesse sentido, a leitura do texto do Kóho Yoko Hovôvo no Acampamento Mãe Terra cumpriu o papel defendido pelo Professor Genésio durante a discussão feita inicialmente nas oficinas sobre a decisão de se escrever o texto com essa temática, como se pode perceber na seguinte fala: "Já é um texto de convencer o povo Terena pensar". O texto se constitui em um instrumento de construção de identidade combativa de resistência dos Terena.

A leitura do texto no Acampamento Mãe Terra mostra ainda o papel da escola como provedora de letramento (como a produção desse texto), mas não com poder para fazê-lo circular socialmente, o que depende da forma especifica como a comunidade local significa a escrita. Para isso, concorreu o agenciamento dos professores Terena ([nós] como acadêmicos, 
Prof. Genésio Farias), com formação superior, como intelectuais em seu contexto sociocultural (Kincheloe, 1997; Giroux, 1997) ao utilizaram, significativamente, o texto no Acampamento Mãe Terra.

\section{Referências}

BRASIL. Constituição: República Federativa do Brasil. Brasília: Senado Federal, 1988.

CAVALCANTI, Marilda C.; MAHER, Terezinha, M. $O$ índio, $a$ leitura e a escrita: o que está em jogo? Campinas: CEFIEL/IEL/UNICAMP, 2005.

D’ANGELIS, Wilmar. R. Línguas indígenas precisam de escritores? Como formá-los? Campinas: CEFIEL/IEL/UNICAMP, 2005.

DIRETRIZES PARA A POLÍTICA NACIONAL DE EDUCAÇÃO ESCOLAR INDÍGENA. Brasília:MEC, SEF, 1993. 22p. (Cadernos educação básica. Série institucional, 2).

GIROUX. Henry. A. Os professores como intelectuais: rumo a uma pedagogia crítica da aprendizagem. Tradução de Daniel Bueno. Porto Alegre: Artes Médicas, 1997.

GOODY, John. (Ed.). Literacy in tradicional societies. Cambridge: Cambridge University Press, 1968.

. The domestication of the savage mind. Cambridge: Cambridge University Press,1977.

. The interface between the written and the oral. Cambridge: Cambridge University Press, 1987.

HORNBERGER, Nancy. H. Continua of biliteracy. Review of Educational Research, v. 59, n. 3, p. 271-296, 1989. 
Language planning from the bottom up. In: Hornberger, N. H. (Org.). Indigenous literacies in the Americas: language planning from the bottom up. Berlim: Mouton de Gruyter, 1996, p. 216-236.

. Criando contextos eficazes de aprendizagem para o letramento bilíngüe. Tradução de Ana Antônia de AssisPeterson e Maria Inês Pagliari Cox. In: COX, Maria Inês P.; ASSIS-PETERSON, Ana Antonia. (Orgs.). Cenas de sala de aula. Campinas, SP: Mercado de Letras, 2001. p. 23-50.

(Ed.). Continua of biliteracy: an ecological framework for educational policy, research and practice in multilingual settings. Clevedon, UK: Multilingual Matters, 2003.

KINCHELOE, J. L. A formação do professor como compromisso político: mapeando o pós-moderno. Tradução de Nize Maria Campos Pellanda. Porto Alegre: Artes Médicas, 1997.

LADEIRA, Maria Elisa M. Língua e história- análise sociolingüística em um grupo terena. 2001, 185 f. Tese (Doutorado em Linguistica) - Faculdade de Filosofia Letras e Ciências Humanas, USP, São Paulo. 2001.

LEVI-STRAUSS, Claude. Lição de escrita. In: Tristes trópicos. Lisboa: Edições 70, 1986. p.290-301.

LOPEZ, Luis E. To Guaranize: a verb actively conjugated by the Bolivian Guaranis. In: HORNBERGER, Nancy .H. (Org). Indigenous literacies in the Americas: language planning from the bottom up. Berlin: Mouton, 1996 p. 321-353.

MAHER, Terezinha. M. Uma pequena grande luta: a escrita e o destino das línguas indígenas acreanas. In: Mota, K.; Scheyerl, D. (Orgs.). Espaços lingüísticos: resistências e expansões. Salvador: EDUFBA, 2006 b, p. 285-310. 
. Do casulo ao movimento: a suspensão das certezas na educação bilíngüe e intercultural. In: Cavalcanti. Marilda C.; Bortoni-Ricardo, S. M. (Orgs.). Transculturalidade, linguagem e educação. Campinas, SP: Mercado de Letras, 2007a, p. 67-94

A educação do entorno para a interculturalidade e o plurilinguismo. In Kleiman, Angela B.; Cavalcanti, Marilda C. (Orgs.). Lingüística aplicada: faces e interfaces. Campinas, SP: Mercado de Letras, 2007b, p. 255-270.

MELIÁ, Bartolomeu. Bilingüismo e escrita. In: D'Angelis, W.; Veiga, J. (Orgs.). Leitura e escrita em escolas indígenas (Encontros de Educação Indígena. COLE nº 10 - 1995). Campinas: ALB/Mercado de Letras, 1997, p. 89-104.

RESOLUÇÃO CEB $N^{o}$ 3. Brasília: Conselho Nacional de Educação/ Câmara de Educação básica, 1999.

MONSERRAT, Ruth. O que é ensino bilíngüe: a metodologia da gramática contrastiva. Em Aberto, Brasília: ano 14, n. 63, Jul/set. 1994, p.11-17.

. Política e planejamento lingüístico nas sociedades indígenas do Brasil hoje: o espaço e o futuro das línguas modernas. In: VEIGA, Juracilda; SALANOVA, Andrés. (Orgs.). Questões de educação escolar indígena: da formação do professor ao projeto de escola. Brasília: FUNAI/DEDOC. Campinas/ALB., 2001, p 127-159.

MORI, Angel. C. Conteúdos lingüísticos e políticos na definição de ortografias das línguas indígenas. In: D'Angels, W.; Veiga, J. (Orgs.). Leitura e escrita em escolas indígenas (Encontros de Educação Indígena) COLE $\mathrm{n}^{\circ} 10$ - 1995. Campinas: ALB/Mercado de Letras, 1997, p. 23-33.

A língua indígena na escola indígena: quando, para que e como? In: Veiga, J.; Salanova, A. (Orgs.). Questões de educação escolar indígena: da formação do professor ao projeto de escola. Brasília: FUNAI/DEDOC. Campinas/ALB, 2001, p. 
160-171.

NINCAO, Onilda S. Representações de professores indígenas sobre o ensino da língua Terena na escola. São Paulo/SP: PUCSP. Dissertação de Mestrado, 2003.

"Kóho Yoko Hovôvo/O Tuiuiú e o Sapo":

identidade, biletramento e política lingüística na formação continuada de professores Terena. Campinas, SP: [s.n.]. Tese (doutorado) - Universidade Estadual de Campinas, Instituto de Estudos da Linguagem, 2008.

OLIVEIRA, Roberto C. Urbanização e tribalismo. a integração dos índios Terêna numa sociedade de classes. Rio de Janeiro: Zahar Editores, 1968.

. Do índio ao bugre: o processo de assimilação dos Terêna. Rio de Janeiro: Francisco Alves, 1976.

. Caminhos da identidade: ensaios sobre etnicidade e multiculturalismo. São Paulo: EditoraUnesp; Brasília:Paralelo $15,2006$.

OLSON, David R. $O$ mundo no papel: as implicações conceituais e cognitivas da leitura e da escrita. São Paulo, Ática, 1997.

ONG, Walter. Writing is a technology that restructures thought. In: BAUMAN, G. (Org.). The written word: literacy in transition. Oxford: Oxford University Press, 1986.

REFERENCIAL CURRICULAR NACIONAL PARA AS ESCOLAS INDÍGENAS (RCNEI). Brasília: MEC/SEF/Coordenação Geral de Apoio às Escolas Indígenas, 1998.

STREET, Brian V. Literacy in theory and practice. New York; Cambridge: Cambridge University Press, 1984.

- (Org.). Cross-cultural approaches to literacy.

Horizontes de Linguística Aplicada, ano 11, n. 2, jul./dez. $2012 \quad 101$ 
Cambridge: Cambridge University Press, 1993.

- Perspectivas interculturais sobre o letramento.

Filologia e Lingüística Portuguesa, n. 8, p. 465-488, 2006.

VEIGA, Juracilda. Professores Kaingang de Inhacorá (RS): uma experiência de formação. In: VEIGA, J.; SALANOVA, Andrés. (Orgs.). Questões de educação escolar indígena: da formação do professor ao projeto de escola. Brasília: FUNAI/DEDOC. Campinas/ALB, 2001, p. 113-126.

VÓVIO. Cláudia. L.; SOUZA, A. L. S. Desafios metodológicos em pesquisas sobre letramento. In: Kleiman, Angela B.; Matêncio, Maria LoPARAurdes. M. (Orgs.). Letramento e formação de professor: práticas discursivas, representações e construção do saber. Campinas - SP: Mercado de Letras, 2005.

Recebido em: 21/11/2012 Aceito em: 12/03/2013

Title: An event of (bi)literacy in indigenous language: reflections of a Terena linguistic policy 